\title{
TENSÕES ENTRE POLÍTICAS PÚBLICAS EDUCACIONAIS E IN(EX)CLUSÃO ESCOLAR DE ALUNOS SURDOS: ECOS DE UM SILENCIAMENTO?
}

\author{
TENSIONES ENTRE LAS POLÍTICAS EDUCATIVAS PÚBLICAS Y EN LA IN(EX) \\ CLUSIÓN ESCOLAR DE ESTUDIANTES SORDOS: ¿ ECOS DE UN SILENCIO?
}

\author{
TENSIONS BETWEEN PUBLIC EDUCATIONAL POLICIES AND SCHOOL \\ IN(EX)CLUSION OF DEAF STUDENTS: ECHOES OF SILENCE?
}

\author{
Hector Renan da Silveira CALIXTO ${ }^{1}$ \\ Amélia Escotto do Amaral RIBEIRO ${ }^{2}$ \\ Tânia Suely Azevedo BRASILEIRO 3
}

\begin{abstract}
RESUMO: Este texto se inscreve no campo das discussões sobre como a inclusão escolar de surdos têm sido contemplada pelas políticas públicas brasileiras, desde a Lei de Diretrizes e Bases da Educação Nacional (1996). Analisam-se tensões entre a letra do texto legislativo e as suas formas de apropriação em contextos escolares. Apoiando-se nos princípios da análise documental e da análise de conteúdo, discutem-se em narrativas de professores de escolas públicas da Baixada Fluminense/RJ percepções sobre a efetividade de processos inclusivos para melhoria da condição humana do sujeito surdo. Os resultados apontam que há uma percepção de distanciamento entre as políticas públicas educacionais e as suas condições de efetivação, e existe a necessidade de discussões mais amplas envolvendo os sujeitos público-alvo dessas políticas, na maioria das vezes silenciados. Assim, é possível entender a garantia dos direitos fundamentais, para além da escola, a partir da escola.
\end{abstract}

PALAVRAS-CHAVE: Políticas públicas educacionais. Inclusão. Surdo.

RESUMEN: Este texto es parte del campo de discusiones sobre cómo la inclusión escolar de las personas sordas ha sido contemplada por las políticas públicas brasileñas, a partir de la Ley de Lineamientos y Bases de la Educación Nacional (1996). Se analizan las tensiones entre la letra del texto legislativo y sus formas de apropiación en los contextos escolares. Partido de los principios del análisis documental y análisis de contenido, las percepciones sobre la efectividad de los procesos inclusivos para mejorar la condición humana del sujeto sordo se discuten en las narrativas de los docentes de escuelas públicas de la Baixada Fluminense / RJ. Los resultados indican que existe una percepción de distanciamiento entre las políticas públicas educativas y sus condiciones de efectividad, y se requiere de discusiones más amplias que involucren al público objetivo de estas políticas, la mayoría de las veces silenciadas. Así,

${ }^{1}$ Universidade Federal do Oeste do Pará (UFOPA), Santarém - PA - Brasil. Doutorando no Programa de PósGraduação em Educação. ORCID: https://orcid.org/0000-0002-4227-6625. E-mail: hectorscalixto@gmail.com

${ }^{2}$ Universidade do Estado do Rio de Janeiro (UERJ), Duque de Caxias - RJ - Brasil. Professora Associada na Faculdade de Educação da Baixada Fluminense. Doutorado em Educação (PUC-Rio). ORCID: https://orcid.org/0000-0001-6218-4173. E-mail: febf.gelcs@gmail.com

${ }^{3}$ Universidade Federal do Oeste do Pará (UFOPA), Santarém - PA - Brasil. Professora Titular no Instituto de Ciências da Educação. Doutorado em Educação (URV) - Espanha. ORCID: https://orcid.org/0000-0002-84234466. E-mail: brasileirotania@gmail.com

RIAEE - Revista Ibero-Americana de Estudos em Educação, Araraquara, v. 15, n. esp. 3, p. 2429-2445, nov., 2020. E-ISSN: 1982-5587 
es posible entender la garantía de los derechos fundamentales, más allá de la escuela, desde la escuela.

PALABRAS CLAVE: Políticas públicas educativas. Inclusión. Sordo.

ABSTRACT: This text is part of the field of discussions on how the school inclusion of deaf people has been contemplated by Brazilian public policies, since the Law of Guidelines and Bases of National Education (1996). Tensions between the letter of the legislative text and its forms of appropriation in school contexts are analyzed. Based on the principles of document analysis and content analysis, perceptions about the effectiveness of inclusive processes to improve the human condition of the deaf subject are discussed in the narratives of public school teachers in Baixada Fluminense/RJ. The results indicate that there is a perception of distance between public educational policies and their conditions of effectiveness, and there is a need for broader discussions involving the target audience of these policies, most of the times silenced. So, it is possible to understand the guarantee of fundamental rights, beyond the school, from the school.

KEYWORDS: Educational public policies. Inclusion. Deaf.

\section{Palavras iniciais}

Este artigo analisa a forma como a legislação educacional brasileira tem contemplado a questão da inclusão escolar de surdos, buscando explicitar as tensões entre a letra do texto legislativo e as suas formas de apropriação em contextos escolares, especialmente por professores. Tomam-se como foco de análise a legislação que compreende a promulgação da Lei de Diretrizes e Bases da Educação Nacional (LDBEN) - Lei 9.394/1996 até a Lei Brasileira de Inclusão (LBI) - Lei $\mathrm{n}^{\mathrm{o}}$ 13.146/2016. Observa-se, nesse período, em contatos formais e informais com situações de cotidiano escolar, que as determinações oficiais nem sempre são compreendidas, e até mesmo conhecidas, pelos diferentes atores da escola. Os que mais se ressentem de conhecimento, entendimento e esclarecimento mais efetivos são os professores. Certamente porque estes são chamados a atender a uma nova demanda para a qual não estão nem informados nem preparados. Esse é um cenário bastante recorrente principalmente na escola pública. E, é no interior dessa escola que emergem angústias das mais variadas naturezas, as quais, em alguns casos, resultam em demandas por formação.

Embora se reconheça a importância de ações com vistas a uma sociedade inclusiva, menos segregadora e preconceituosa, essa dimensão inclusiva, principalmente da educação e da escola, ainda é recente no contexto brasileiro. Isso se reflete nos textos legislativos. Nestes, observa-se, independentemente de marcação temporal específica, as seguintes perspectivas: a inclusão ligada à incapacidade e às necessidades educacionais especiais; a inclusão como 
resposta às exclusões disciplinares; a inclusão voltada a todos os grupos vulneráveis à exclusão; a inclusão como promoção de uma escola para todos; e a inclusão como Educação para Todos (AINSCOW; MILES, 2013).

Especificamente em relação à inclusão escolar do surdo, no contexto brasileiro, durante muito tempo a educação dos surdos foi incorporada à educação especial. E, de forma ainda tímida, vem sendo contemplada de forma específica. Dentre as políticas públicas voltadas para essa comunidade, destaca-se a Lei $n^{0} 10.436$, de 24 de abril de 2002, que reconhece a Libras como meio legal de comunicação e expressão dos surdos (BRITO; NEVES; XAVIER, 2013). A respeito da Libras pode-se afirmar o quanto esta tem sido objeto de discussões e contradições no contexto escolar, transformando-se em desafio tanto para professores quanto para alunos, ouvintes e surdos. Esse desconforto se complexifica com o advento da abordagem inclusiva bilingue (Cf. FERNANDES; MOREIRA, 2014).

Assim, considerados os textos legislativos, a análise se ocupa “[...] das contradições internas às formulações, porto que os textos evidenciam vozes discordantes, em disputa. É nesse campo que a 'hegemonia discursiva' se produz" (SHIROMA; CAMPOS; GARCIA, 2005, p. 431). Portanto, o presente artigo, apoiando-se nos princípios da análise documental e da análise de conteúdo, discute, a partir de narrativas de professores de escolas públicas da Baixada Fluminense/RJ, percepções sobre a efetividade de processos inclusivos para melhoria da condição humana do sujeito surdo.

Do ponto de vista da organização, apresentam-se os eixos que organizam as reflexões apresentadas: inclusão escolar: conceitos e proposições; a inclusão escolar do surdo na legislação brasileira; a inclusão escolar do surdo na legislação brasileira; o que revelam as narrativas de professores de escolas públicas.

\section{Inclusão escolar: conceitos e proposições}

É importante reconhecer que tanto a Educação Especial como, sobretudo, a inclusão, apresentam-se como desafios permanentes tanto do ponto de vista da proposição de políticas públicas e das ações que delas decorrem quanto da produção acadêmica nesse campo. Esses desafios, na maioria das vezes, se devem ao fato dessas temáticas se referirem a questões que a sociedade, tradicionalmente, tem tido dificuldade de enfrentar, quer por desconhecimento e não vivência quer por preconceito ainda não superado.

Quando tratam da importância dos temas Educação especial e inclusão, apontando para a importância da produção de conhecimento neste campo/área, Rocha, Reis e da Costa (2020) 
consideram a necessidade das reflexões se organizarem a partir da tríade pesquisa, políticas e práticas. Consideram-nas relevantes na medida em que cada um desses componentes da tríade está intrinsecamente relacionado. Por exemplo, do ponto de vista das práticas, nem sempre os contextos escolares conseguem superar seus modelos e concepções curriculares tradicionais e segregadores. Boa parte das escolas ainda apresenta dificuldades para garantir os direitos de aprendizagem para todos. Em relação às tendências das pesquisas no campo da inclusão/educação especial pode-se perceber que, apesar das incertezas quanto às escolhas metodológicas mais adequadas, têm sido utilizadas pesquisas narrativas, pesquisas de abordagem fenomenológica e estudos de casos.

Entendendo que as políticas públicas se constituem, inegavelmente, como instrumentos de regulação, Lemes (2016) aponta como estruturadores desse entendimento os conceitos de "diretrizes, metas, estratégias e regulação". Considera que esses conceitos, quando incorporados às narrativas utilizadas na proposição das políticas, transformam-se em “argumentos, procedimentos e processos através dos quais a ação pública é estabelecida, promovida, orientada e coordenada, tendo como finalidade alcançar soluções desejáveis, em relação a situações problemas" (LEMES, 2016, p. 1618). Nesse sentido, o autor se apoia em Afonso (2006) para ratificar que:

[...] a regulação das políticas públicas e da acção pública, em educação, é concebida como um processo composto por um complexo conjunto de acções e interacções, realizadas por múltiplos actores, produzindo a coordenação da acção colectiva na oferta da educação como bem público (AFONSO, 2008, p. $6)$.

Merece destaque, aqui, as articulações que o autor estabelece, na perspectiva das políticas públicas, entre “ações públicas, ações e interações entre múltiplos atores, ação coletiva e bem público". Tem-se indicadas aqui as finalidades teleológicas da sociedade, sobretudo a democrática, no sentido da busca da melhoria permanente da condição humana na perspectiva da inserção na dinâmica da vida em sociedade.

A respeito das políticas públicas, Rocha, Reis e da Costa (2020), enfocam-nas em termos da existência ou da falta, reconhecendo-as como essenciais para a efetivação de modelos societários e educacionais mais inclusivos. Essa essencialidade das políticas públicas para a operacionalização de ações inclusivas fica evidente, se consideradas como o processo histórico da sociedade avançou, ou tentou avançar, em relação à deficiência e aos deficientes. Assim, desde o século XVIII, podem-se identificar ações políticas que, mesmo sem a intenção de inclusão, servem de marcos para o reconhecimento desses sujeitos. Especificamente no Brasil, 
a educação especial tem início no século XIX, com a criação de instituições hoje conhecidas como Instituto Benjamin Constant (IBC) e Instituto Nacional de Educação de Surdos (INES), voltadas para pessoas com deficiência (ROCHA; REIS; DA COSTA, 2020).

Face às dinâmicas dos cenários político, econômico, social, cultural e religioso experimentados no século XX, sociedades e países sentiram a necessidade de políticas públicas que considerassem a inserção dos deficientes na sociedade. No campo educacional, servem de exemplo documentos como a Declaração de Jomtien - Tailândia (UNESCO, 1990); e a Declaração de Salamanca - Espanha (UNESCO, 1994), que propuseram orientações para a inclusão "de todas as pessoas nas escolas comuns".

Certamente esta não é uma tarefa fácil. Os autores (ROCHA; REIS; DA COSTA, 2020) quando se referem, nesse particular, à função das escolas e universidades enquanto locais de produção de saber, assinalam, inspirando-se em Belloni (1992) quando afirma:

É um saber comprometido com a verdade porque ela é a base da construção do conhecimento. Um saber comprometido com a justiça porque ela é a base das relações humanas. Um saber comprometido com a beleza porque ela possibilita a expressão da emoção e do prazer [...]. Um saber comprometido com a igualdade porque ela é a base da estrutura social inerente à condição humana. Um saber comprometido com o verdadeiro, o justo, o igualitário e o belo; é, em verdade, um compromisso com a transformação da sociedade, pois esses não são valores predominantemente estabelecidos e praticados na organização da vida humana, apesar de lhes serem próprios e inerentes (BELLONI, 1992, p. 73).

Retomando a função reguladora das políticas públicas, no contexto brasileiro, a redemocratização se mostra como decisiva para novos encaminhamentos nesse campo, sobretudo, no que se refere às políticas sociais. Esse cenário se torna profícuo para os estudos que se ocupam em estudar esse conjunto de políticas. Do ponto de vista metodológico, os estudos pautados na análise cognitiva das políticas têm contribuído para um melhor entendimento das ações e dos atores nelas envolvidos. Sobretudo em relação às ações do poder público sobre o sistema educativo, ainda há muito a investigar no sentido de explicitar os fundamentos que norteiam as decisões e proposições. E, ainda, ter em conta o distanciamento que se observa entre as proposições legislativas e as expectativas dos sujeitos para os quais se destinam de forma direta ou indireta, considerando as demandas qualitativas em relação aos sistemas educacionais (LEMES, 2016). 


\section{A inclusão escolar do surdo na legislação brasileira: ausências?}

Em termos do conjunto dos marcos legislativos que orientam, direta ou indiretamente, a educação de surdos, o Quadro 1, a seguir, sistematiza-os cronologicamente.

Quadro 1 - Principais marcos políticos e legais que envolvem a Educação de Surdos

\begin{tabular}{|c|c|c|}
\hline Ano & Documento & Assunto / Temática / Título \\
\hline 1996 & Lei ${ }^{\circ} 9.394-$ LDB & Estabelece as diretrizes e bases da educação nacional. \\
\hline 2001 & Lei $\mathrm{n}^{\circ} 10.172$ & $\begin{array}{l}\text { Aprova o Plano Nacional de Educação e dá outras } \\
\text { providências. }\end{array}$ \\
\hline 2001 & $\begin{array}{c}\text { Resolução CNE/CNB n } \\
2\end{array}$ & $\begin{array}{l}\text { Institui Diretrizes Nacionais para a Educação Especial na } \\
\text { Educação Básica. }\end{array}$ \\
\hline 2002 & Lei $n^{\circ} 10.436$ & $\begin{array}{l}\text { Dispõe sobre a Língua Brasileira de Sinais - Libras e dá } \\
\text { outras providências. }\end{array}$ \\
\hline 2005 & Decreto $n^{\circ} 5.626$ & $\begin{array}{l}\text { Regulamenta a Lei } \mathrm{n}^{\circ} 10.436 \text {, de } 24 \text { de abril de } 2002 \text {, que } \\
\text { dispõe sobre a Língua Brasileira de Sinais - Libras, e o art. } \\
18 \text { da Lei } \mathrm{n}^{\circ} 10.098 \text {, de } 19 \text { de dezembro de } 2000 \text {. }\end{array}$ \\
\hline 2008 & $\begin{array}{c}\text { Política Nacional de } \\
\text { Educação Especial na } \\
\text { Perspectiva da Educação } \\
\text { Inclusiva }\end{array}$ & $\begin{array}{l}\text { O Ministério da Educação/Secretaria de } \\
\text { Continuada, Alfabetização, Diversidade e Inclusão } \\
\text { apresenta a Política Nacional de Educação Especial na } \\
\text { Perspectiva da Educação Inclusiva, que acompanha os } \\
\text { avanços do conhecimento e das lutas sociais, visando } \\
\text { constituir políticas públicas promotoras de uma educação } \\
\text { de qualidade para todos os estudantes. }\end{array}$ \\
\hline 2014 & Lei $n^{\circ} 13.005$ & $\begin{array}{l}\text { Aprova o Plano Nacional de Educação - PNE e dá outras } \\
\text { providências. }\end{array}$ \\
\hline $2015 / 2016^{4}$ & Lei $\mathrm{n}^{\circ} 13.146$ & $\begin{array}{l}\text { Institui a Lei Brasileira de Inclusão da Pessoa com } \\
\text { Deficiência (Estatuto da Pessoa com Deficiência). }\end{array}$ \\
\hline
\end{tabular}

Fonte: elaboração dos autores (2020)

Alguns pontos merecem destaque em relação à educação de surdos, a partir de cada um dos documentos listados. A Lei de Diretrizes e Bases da Educação Nacional (1996) faz alusão à Educação Especial, considerando-a como uma modalidade de Educação Escolar destinada a alunos portadores de necessidades especiais. $\mathrm{O}$ atendimento a esses alunos seria feito nas escolas regulares. $\mathrm{O}$ conceito de alunos portadores de necessidades especiais passa a ser utilizado para abranger todo o conjunto de necessidades especiais, inclusive as específicas. $\mathrm{O}$ art. 59 indica a necessidade de adequações curriculares e nos espaços físicos, de modo a garantir que todos possam ser atendidos. Cabe acrescentar que a inclusão escolar dos surdos estava contemplada nessa concepção mais ampla de necessidades especiais, uma vez que ainda não havia uma orientação específica. Também, chama atenção que no texto da Lei predomina o uso do termo deficiência, seguido de inclusão.

\footnotetext{
${ }^{4}$ A LBI foi publicada em julho de 2015, mas com vigência a partir do ano de 2016, por isso considera-se, no
} contexto desse trabalho, como efeito prático o ano de 2016.

RIAEE - Revista Ibero-Americana de Estudos em Educação, Araraquara, v. 15, n. esp. 3, p. 2429-2445, nov., 2020. E-ISSN: 1982-5587 
A Lei nº 10.172 que aprova o Plano Nacional de Educação - PNE, na seção que trata da Educação Especial, especificamente em relação à Educação de Surdos, apresenta como objetivos e metas: "11. Implantar, em cinco anos, e generalizar em dez anos, o ensino da Língua Brasileira de Sinais para os alunos surdos e, sempre que possível, [...] para o pessoal da unidade escolar" (BRASIL, 2001, anexo). O PNE marca o início do processo de reconhecimento da Língua Brasileira de Sinais como meio de comunicação dos alunos surdos. Também é interessante observar, do ponto de vista da nomenclatura utilizada, que no PNE há um predomínio do termo inclusão.

A Resolução CNE/CEB n 2/2001 (CNE/CEB/BRASIL, 2001), ao estabelecer diretrizes para a Educação Especial, faz referência ao paradigma da Educação Inclusiva. Em seu art. $2^{\circ}$, determina a matrícula de todos os alunos nos sistemas de ensino, e às escolas recomenda que se organizem para o atendimento aos educandos com necessidades educacionais especiais, assegurando-lhes as condições necessárias para uma educação de boa qualidade para todos. Não há alusão explícita aos surdos, sendo estes incluídos no art. $5^{\circ}$, onde são designados como aqueles com "dificuldades de comunicação e sinalização diferenciada dos demais alunos, demandando a utilização de linguagens e códigos aplicados" (BRASIL, 2001). O art. 12, parágrafo $2^{\circ}$, faz referência ao uso de linguagem adequada: "como o sistema Braille e a língua de sinais, sem prejuízo do aprendizado da Língua Portuguesa [...]”. Observa-se nesse parágrafo a referência ao aprendizado da Língua Portuguesa.

A Lei $n^{0} 10.436$ oficializou a Língua Brasileira de Sinais - Libras como meio legal de comunicação e expressão do surdo, e determinou no Art. $4^{\circ}$ a inclusão do ensino de Libras nos cursos de Magistério, tanto em nível médio, quanto em nível superior, como parte integrante dos Parâmetros Curriculares Nacionais - PCNs. E, o Decreto n ${ }^{0}$ 5.626, de 2005, ao regulamentar a Lei 10.436, estabelece algumas orientações: a definição da pessoa surda; a formação dos professores e instrutores de Libras; os exames de proficiência e avaliações; a formação do tradutor/ intérprete de Libras/ Língua Portuguesa; e a garantia dos direitos dos surdos à educação e à saúde. Também, o Decreto reforçou a inclusão da disciplina de Libras na grade curricular de todos os cursos de formação de professores para o exercício do magistério, que são "todos os cursos de licenciatura, nas diferentes áreas do conhecimento, o curso normal de nível médio, o curso normal superior, o curso de Pedagogia e o curso de Educação Especial" (BRASIL, 2005, Art. $3^{\circ}$ ). Garante-se a abordagem bilíngue para referência para o processo educacional dos surdos.

Na perspectiva da Política Nacional de Educação Especial na Perspectiva da Educação Inclusiva (2008), em se tratando dos alunos surdos: 
[...] é necessário reinventar as formas de conceber a escola e suas práticas pedagógicas, rompendo com os modos lineares do pensar e agir no que se refere à escolarização. O paradigma inclusivo não se coaduna com concepções que dicotomizam as pessoas com ou sem deficiência, pois os seres humanos se igualam na diferença, refletida nas relações, experiências e interações. As pessoas com surdez não podem ser reduzidas à condição sensorial, desconsiderando as potencialidades que as integram a outros processos perceptuais, enquanto seres de consciência, pensamento e linguagem (MEC/SEESP, 2010, p. 8).

O bilinguismo, na indicação desse documento, destaca a liberdade do aluno se expressar em uma ou em outra língua e de participar de um ambiente escolar que desafie seu pensamento e exercite sua capacidade perceptivo-cognitiva, suas habilidades para atuar e interagir em um mundo social que é de todos, considerando o contraditório, o ambíguo, as diferenças entre as pessoas (MEC/SEESP, 2010).

A Lei n ${ }^{\circ}$ 13.005 PNE 2014-2024, destaca na estratégia 4.1: "Garantir a oferta de Educação bilíngue, em Língua Brasileira de Sinais (libras) como primeira língua e na modalidade escrita da língua portuguesa como segunda língua, aos alunos surdos e deficientes auditivos de 0 a 17 anos, em escolas e classes bilíngues inclusivas” (BRASIL, 2014)

A Lei no 13.146/2015, denominada de Lei Brasileira de Inclusão - LBI, aponta, ainda que timidamente, Educação Especial na perspectiva da Educação Inclusiva. Ratifica a "oferta de educação bilíngue, em Libras como primeira língua e na modalidade escrita da Língua Portuguesa como segunda língua, em escolas e classes bilíngues e em escolas inclusivas" (BRASIL, 2015, Art. 28). Assegura, assim, a educação bilíngue para surdos. Isso sugere a necessidade de reorganização dos sistemas, em seus diferentes níveis.

O conjunto das determinações legislativas, pelo que se observa nos seus textos, permite depreender a ênfase, apontada na literatura, em aspectos como: adequações curriculares, o ensino da Língua Brasileira de Sinais, inclusão, classes bilíngues inclusivas, modalidade escrita da Língua Portuguesa, reinvenção dos modos de pensar a escola e suas práticas pedagógicas; as condições necessárias para uma educação de boa qualidade para todos. É curioso o fato de que o foco se volta predominantemente para os espaços escolares e, nestes, para dois pontos: a língua e a dimensão pedagógica na perspectiva da educação inclusiva. 


\section{O professor e a dimensão inclusiva da escola}

Para discutir aspectos relacionados a como professores se relacionam e constroem modos de perceber a questão da inclusão no contexto escolar, Heredero e Anache (2020) chamam atenção para o quanto a Declaração de Salamanca foi decisiva para as proposições das políticas em educação inclusiva, principalmente para a inclusão escolar, destacando:

[...] as escolas regulares, seguindo esta orientação inclusiva, constituem os meios mais capazes para combater as atitudes discriminatórias, criando comunidades abertas e solidárias, construindo uma sociedade inclusiva e atingindo a educação para todos; além disso, proporcionam uma educação adequada à maioria das crianças e promovem a eficiência, numa óptima relação custo-qualidade, de todo o sistema educativo (BRASIL,1994, p. VIII).

Os autores retomam a ideia de que a inclusão escolar representa um esforço coletivo que envolve todo o conjunto de atores escolares, como "alunos, professores, gestores, demais funcionários, famílias, poder público e sociedade”. Esse esforço não é somente de intenções e proposições, mas principalmente de ações para além da inclusão dos deficientes no espaço físico escolar. O que se busca é garantir a esses alunos uma aprendizagem efetiva, ajustada às características e possiblidades educativas de cada um. Para que isso ocorra são necessárias reformulações das práticas educativas e de aprendizagem utilizadas até então, tornando-as inclusivas. E com isso, promover a redução das desigualdades e injustiças sociais através de uma revisão permanente dos objetivos às condições de aprendizagem, de modo a articular as dimensões sociais e pessoais dos sujeitos envolvidos. Cabe acrescentar que uma prática inclusiva é sempre uma prática contextualizada, singular e destinada a finalidades e contextos específicos. Uma prática não se torna inclusiva em si mesma; depende de quem a operacionaliza e de como é operacionalizada.

Especificamente no que se refere à formação de professores, esta se faz essencial para repensar as ações didático-pedagógicas, instrumentalizando-os para uma atuação mais efetiva. Na maioria dos contextos escolares o que se observa é que, embora os discursos dos professores admitam e reconheçam a importância da inclusão escolar, quando se trata de organizar as experiências de aprendizagem voltadas para os alunos incluídos, sentem-se inseguros e céticos.

Considera-se importante assinalar que, no contexto da educação inclusiva e da inclusão escolar, o professor e sua formação ganham destaque não no sentido da proposição de ações específicas de formação nesses campos, mas de uma polarização nas questões didáticopedagógicas do trabalho com alunos deficientes, sobretudo com alunos surdos. E, nesse sentido da ênfase aos aspectos pedagógicos, vários ponttos têm sido trazidos à reflexão. Um deles 
aponta para as tensões da didática na educação básica (HAAS; TEZZARI, 2014). As autoras, ao abordarem especificamente os processos escolares inclusivos, destacam em suas contribuições as questões das escolhas didáticas como eixo e o conceito de momento pedagógico. Se apoiam na definição de Meirieu (2002) quando afirma:

O momento pedagógico pode ser compreendido como esse encontro exigente de duas pessoas que se envolvem em uma partida em que nada é jogado com antecedência e em que a 'dureza' do objeto de transação, sua coerência interna, sua estrutura própria regula permanentemente a relação. É nisso que o momento pedagógico, embora remeta inevitavelmente a uma relação entre dois parceiros, nada tem a ver com o 'relacional' concebido como a mera empatia recíproca de duas subjetividades que se expandem. $\mathrm{O}$ que separa irremediavelmente o 'relacional' do 'pedagógico' é o controle sobre o objeto de transação interindividual, o trabalho comum de elucidação do que se deve compreender que se diz, do que se deve partilhar na compreensão daquilo que se transmite (MEIRIEU, 2002, p. 90).

Ainda nessa perspectiva, mesmo que evidentes as intencionalidades e finalidades da educação escolar e, neste caso, da educação inclusiva, fica evidente o esforço necessário para tornar os objetos de aprendizagem mais significativos para os alunos. A relação pedagógica é essencialmente marcada pela tensão entre o planejado e o imprevisto. Dessa tensão se espera o surgimento de novos modos de organizar as experiências de ensino e de aprendizagem. Assim:

[...] um olhar voltado às necessidades e às singularidades dos cotidianos escolares é tomado como dispositivo potente para compreendermos que as rotinas pedagógicas não precisam ser novas ou originais para se inscreverem como práticas e condutas pedagógicas inovadoras. A inovação surge da percepção da rotina que perfaz o cotidiano para além da mera repetição de rituais ou como rotina não rotineira e do imprevisto como elemento que, tomado em sua complexidade, com investimento pedagógico, pode ser disparador de processos de mudanças qualitativas no cotidiano escolar (HAAS; TEZZARI, 2014, p. 79).

As autoras acrescentam:

Escolarizar toda a população de uma sociedade é um projeto audacioso, mas do qual não se pode abrir mão, sob pena de inviabilizar a própria atribuição e sentido existencial da escola. O pedagogo não pode desistir e deixar-se levar por ideias e valores arraigados como verdades imutáveis, por exemplo, a crença determinista de que alguns sujeitos com determinadas características ou provenientes de circunstâncias sociais específicas não estariam aptos para aprender (HAAS; TEZZARI, 2014, p. 95).

Pode-se perceber, como já assinalado, uma tendência para um olhar voltado para a escola, seus sujeitos e contextos que, embora não desconsidere, pode silenciar outras questões de fundo, especialmente quando se trata da inclusão escolar de alunos surdos. A esse respeito, 
Zajac (2011) problematiza a questão da proposta de uma educação bilíngue. Um contexto escolar bilíngue pressupõe a interação entre professor-ouvinte/aluno-surdo/aluno ouvinte-aluno surdo. Pressupõe também uma linguagem compartilhada, o que na maioria das vezes não ocorre. Essa dificuldade ou inexistência de uma linguagem compartilhada impacta diretamente não apenas a aprendizagem, mas os modos de comunicação e interrelação entre os sujeitos. E nesse cenário, a língua de sinais se mostra fundamental na dinâmica das relações de ensino e de aprendizagem (Cf. GOES; SOUZA, 1997; LACERDA, 1996).

Sobre a redução das discussões sobre inclusão escolar de alunos surdos a questões pedagógicas, metodológicas e práticas, e, consequentemente, à formação e atuação do professor, Bizio (2015) cita Goldfeld (2001) quando alerta para questões de fundo negligenciadas tanto pelos estudos quanto pelas discussões que circulam nesse campo. Questões relacionadas especialmente aos modos como esses "esses sujeitos acedem ao universo simbólico" (GOLDFELD, 2001, p. 46). Em outras palavras,

[...] é necessário deslocar os estudos sobre aquisição da linguagem pelo surdo do palco de discussões ideológicas, e tomá-la como uma questão que merece reflexão teórica particular. O bilinguismo na área da surdez é uma filosofia educacional voltada para educação de surdos que, mais do que uma simples abordagem pedagógica que visa à escolarização de surdos - dado o fracasso escolar por eles enfrentado -, pretende também favorecer e ampliar o desenvolvimento da pessoa surda (BIZIO, 2015, p. 38).

Evidencia-se uma perspectiva mais ampla no sentido de instrumentalizar mais e melhor o aluno surdo para que, respeitado em sua diferença, possa se comunicar melhor nas diferentes esferas da vida em sociedade. Desse modo, torna-se indispensável "um debate mais abrangente que proponha diretrizes para uma política educacional e linguística comprometida com a educação de minorias linguísticas apagadas nos bancos escolares” (LIMA, 2004, p. 49).

A partir do que se apresentou anteriormente, é possível apontar como pontos chave para a reflexão sobre as tensões entre as proposições legislativas e os contextos escolares inclusivos que acolhem alunos surdos, o pouco conhecimento dos atores escolares sobre o surdo e a surdez; as crenças de uns e de outros sobre os potenciais de aprendizagem do aluno surdo; os modos como professores se relacionam com os objetos da aprendizagem a serem mediados, especialmente a língua portuguesa escrita; o pouco (ou nenhum) domínio da Libras pelos atores escolares. Essas questões, na maioria das vezes, dado ao seu imediatismo, acabam silenciando problemáticas mais amplas como uma perspectiva de formação do aluno surdo que tenha, para além do espaço escolar, sua inserção cidadã na sociedade como terminalidade. 


\section{O que revelam as narrativas de professores de escolas públicas}

Para o estudo apresentado neste artigo, foram selecionadas narrativas de 14 professores que atuam na educação de surdos dos anos iniciais do ensino fundamental em redes municipais de ensino da Baixada Fluminense, coletadas em 15 encontros de formação, que foram tomados como grupos focais. Essa forma de coleta de dados proporciona a compreensão das percepções, crenças e atitudes relativas a um determinado tema (KITZINGER, 2000).

Sobre os trechos das narrativas, optou-se por não incluir recortes muito extensos a fim melhor preservar o anonimato dos participantes. A identificação dos sujeitos é realizada por P1 a P14, sendo P representativo de "Professor". O tratamento dos dados inspirou-se na Análise de Conteúdo, que tem como objetivo principal "compreender criticamente o sentido das comunicações, seu conteúdo manifesto ou latente, as significações explícitas ou ocultas" (CHIZZOTTI, 2006, p. 98).

As temáticas identificadas nas narrativas foram organizadas em cinco eixos principais: sobre o desconhecimento do surdo e da surdez; a língua como questão; dimensão pedagógica; o papel do professor; a escola na perspectiva inclusiva. Os trechos citados apresentam ideias recorrentes nas falas dos participantes.

As narrativas indicam que os professores desconhecem conceitos que envolvem a surdez e os sujeitos surdos, como a cultura surda e as formas de como esses sujeitos aprendem e se inscrevem na sociedade. Há uma ausência de experiência em se ter preocupação de pensar a diferença na sala de aula. "Por exemplo, meu irmão é professor há mais de 20 anos, e quando teve um aluno surdo pela primeira vez veio para mim desesperado, sem saber o que fazer." (P2, grifos nossos). "As pessoas [...] não conhecem sobre a surdez, não sabem nada sobre cultura surda, sobre o jeito de ser do surdo" (P5, grifos nossos).

Quando se trata da questão da língua, as narrativas se alinham à legislação e as políticas públicas educacionais, apresentando a língua como eixo estruturador. "Agora comecei a entender que é preciso ter noção de como pensar a língua, ter um olhar de fora para dentro" (P1, grifos nossos). $\mathrm{O}$ trecho de $\mathrm{P} 1$ exemplifica a atenção quase que exclusiva à questão da língua na inclusão escolar do surdo. É curioso observar o quanto a questão da língua permeia inclusive as questões didático-pedagógicas. Os professores quando indicam que é possível pensar em alternativas para sua ação didático-pedagógica, o fazem nessa perspectiva. Isso é observado na fala de P8 (grifos nossos): “Acho que ele vai aprender, mesmo que não seja igual um aluno ouvinte, mas ele vai aprender o principal do português e vai conseguir entender um texto [...]. Saber se tem crase ou não, não é o principal”. 
Em relação ao papel do professor, as narrativas mostram que as políticas públicas, apesar de indicarem a garantia de uma educação bilíngue para os sujeitos surdos, não têm sido efetivas quanto à formação dos professores para atuação em contextos escolares bilíngues e/ou inclusivos. "A gente vai trabalhando, correndo atrás pra tentar entender como funciona o ensino pra surdos, mas não temos um caminho definido a seguir” (P4, grifos nossos). Isso parece indicar um distanciamento entre a letra da lei e os modos de apropriação em contextos de cotidiano escolar. Pode indicar também silenciamento das formas de operacionalização e implementação das políticas públicas voltadas para a educação de surdos. "Não tem uma diretriz, ou um curso específico antes do professor trabalhar com surdos. [...] Por isso, ficamos perdidos no dia a dia, e vamos aprendendo na marra, ou pelo menos achamos que aprendemos" (P4, grifos nossos). Esse "achar que aprende" não se restringe apenas no eixo do ensino, mas também pode ser refletido no eixo da aprendizagem, onde o aluno surdo "acha que aprende". Um jogo de "faz de conta" contraproducente para a educação de surdos, o que levaria a uma falsa sensação de cumprimento da legislação e de atendimento dos anseios do público-alvo dessas políticas, surdos e ouvintes.

Essa dimensão do papel do professor é ampliada quando se trata da escola da perspectiva inclusiva. Quando se toma a questão da língua como central, e quase única, para inclusão educacional do sujeito surdo, há o risco de não se considerar outros elementos facilitadores da inserção social. Não se aponta aqui a língua como não importante, mas sim que ela não seja a única questão a ser tratada nas políticas públicas educacionais e, consequentemente, implementadas no ambiente escolar. "Mas quem não passa por isso de repensar essa estrutura da sala de aula fica naquele sofrimento de sempre, 'o incluído não aprende"' (P2, grifos nossos). A estrutura da sala de aula vai muito além da língua utilizada.

Os professores indicam a necessidade de um ambiente inclusivo, reiterando a escola como "espaço privilegiado da preparação para a cidadania e para o pleno desenvolvimento humano" (FÁVERO, 2004, p. 53). “A escola é um espaço de importante integração social. É importante para o aluno surdo estar ali e ter contato com as outras crianças, para que ele também desenvolva a socialização, se sinta parte da sociedade" (P5, grifos nossos). Ser e fazer parte da sociedade humana, para além de entender e ser entendido por meio de uma língua comum, compreende outros aspectos silenciados tanto na letra da lei quanto nas narrativas. "Além disso é preciso também ter respeito às especificidades do surdo" (P7, grifos nossos). Essas especificidades incluem cultura e identidade, que ainda que indicadas nas políticas como articulações necessárias, não se tornam explícitas no contexto escolar. 
Essa percepção do surdo como sujeito pleno, para além da língua, implica um sólido conhecimento epistemológico por parte do professor. Esses fundamentos contribuem na construção das suas práticas de ensino para alunos surdos. É fundamental o professor refletir, em cada situação, a respeito de quem é o aluno surdo, suas diferenças e potencialidades. E ainda ter ciência de quais são as bases ideológicas em que as suas concepções de ensino estão pautadas, e se essas consideram o aluno surdo como um ser humano pleno, individual e socialmente (DORZIAT, 2004).

\section{Considerações (não) finais}

Analisando-se a letra da lei e como esta é apropriada pelos contextos escolares e seus sujeitos, especialmente os professores, se percebe um foco, quase exclusivo, na questão da língua. Seja a língua de sinais, seja o português escrito, a língua por si só não pode ser pensada como solução única para a inclusão dos sujeitos surdos, não apenas no ambiente escolar, mas na sociedade. Para que a escola na perspectiva inclusiva seja um espaço onde as diferenças se encontram e a cidadania possa ser construída, são necessárias mudanças que promovam o respeito mútuo, o exercício de vivências democráticas, o reconhecimento das diferenças e especificidades dos sujeitos e a busca por forma mais efetivas de inclusão desses sujeitos na sociedade.

O conteúdo das narrativas analisado neste trabalho sugere a essencialidade de reflexões sobre aproximação e/ou contradição entre as reivindicações de diferentes sujeitos e instâncias da sociedade, as proposições legislativas e as formas como uma e outra é apropriada em situações cotidianas. Essas reflexões contribuem para uma maior clareza do que indicam as políticas públicas educacionais e as possibilidades de operacionalização dessas indicações. É preciso contemplar as reais condições de efetivação dessas políticas, considerando diferentes contextos e atores: sociedade, escola, professores e surdos.

Portanto, entende-se que apesar das determinações da lei, o seu texto em si não é suficiente para promover mudanças de percepção da sociedade em relação ao surdo e suas diferenças, não somente linguísticas, mas de identidade e de cultura. Caso não se amplie o campo de diálogo sobre esse conjunto de questões, contrariamente ao que se propõe, ratifica-se o silenciamento dos demais aspectos para além da língua, tanto pela letra da lei quanto pelos sujeitos envolvidos na efetivação das políticas públicas educacionais. Assim, é possível entender a garantia dos direitos fundamentais, para além da escola, a partir da escola. 


\section{REFERÊNCIAS}

AFONSO, N. As metas da aprendizagem: Fundamentos e Características de um instrumento de Regulação nas políticas educativas. In: FIALHO, I.; VERDASCA, J. (Org.). Turma mais e sucesso escolar: fragmentos de um percurso. Portugal: CIEP/EU, Universidade de Évora, 2012.

AINSCOW, M.; MILES, S. Desarrollando sistemas de educación inclusiva. Cómo podemos hacer progressar las políticas de educación? In: GINÉ C.; DURAN, D.; FONT, J.; MIQUEL, E. (Coord.) La educación inclusiva: de la exclusion a la plena participación de todo el alumnado. Barcelona: Horsori Editorial, S.L., 2013

ARNAIZ-SÁNCHEZ, P. A Educação Inclusiva: um meio de construir escolas para todos no século XXI. Revista da Educação Especial, Brasília, v. 1, n. 1, p. 7-18, 14 out. 2005.

BELLONI, I. Função da universidade: notas para reflexão. In: BRANDÃO, Z. et al. Universidade e Educação. Campinas, SP: Papirus: Cedes; São Paulo: Ande: Anped, 1992. (Coletânea C.B.E.)

BIZIO, L. Sobre o modo de relação do surdo com a língua portuguesa escrita. 2015. 75 f. Tese (Doutorado em Linguística Aplicada e Estudos da Linguagem) - Pontifícia Universidade Católica de São Paulo, São Paulo, 2015.

BRITO, F. B.; NEVES, S. L G.; XAVIER, A. N. O movimento surdo e sua luta pelo reconhecimento da Libras e pela construção de uma política linguística no brasil. In: ALBRES, N. A.; NEVES, S. L. G. (Org.) Libras em estudo: política linguística. São Paulo: FENEIS, 2013.

CHIZZOTTI, A. Pesquisa qualitativa em Ciências Humanas e Sociais. 3. ed. Petrópolis: Vozes, 2006.

COSTA, J. P. B. A educação do surdo ontem e hoje, posição sujeito e identidade. Campinas: Mercado das Letras, 2010.

DORZIAT, A. Educação e surdez: o papel do ensino na visão de professores. Educar, Curitiba, n. 23, p. 87-104, 2004.

FÁVERO, E. A. G. Direitos das pessoas com deficiência: garantia de igualdade na diversidade. Rio de Janeiro: WVA, 2004.

FERNANDES, S.; MOREIRA, L. C. Políticas de educação bilíngue para surdos: o contexto brasileiro. Educar em Revista, Edição Especial, n. 2, p. 51-69, 2014.

GÓES, M. C. R.; SOUZA, M. R. A linguagem e as "práticas comunicativas" entre educador ouvinte e aluno surdo. In: CONGRESSO INTERAMERICANO DE PSICOLOGIA, 26., 1997, São Paulo. Anais [...]. São Paulo: PUC-SP, 1997.

GOLDFELD, M. A criança surda: linguagem e cognição numa perspectiva sóciointeracionista. São Paulo: Plexus, 2001. 
HAAS, C.; TEZZARI, M. A didática nos processos escolares inclusivos: entrelaces da memória e do momento pedagógico. Revista Educação em Questão, Natal, v. 49, n. 35, p. 75-98, maio/ago. 2014.

KITZINGER, J. Focus groups with users and providers of health care. In: POPE, C.; MAYS, N. (Org.). Qualitative research in health care. 2. ed. London: BMJ Books, 2000.

LACERDA, C. B. F. Os processos dialógicos entre aluno surdo e professor ouvinte: examinando a construção de conhecimentos. 1996. 135 f. Tese (Doutorado em Educação) Universidade Estadual de Campinas, Campinas, 1996.

LEMES, S. S. Indagações sobre as políticas educacionais e reflexões sobre demandas percebidas pelo estado brasileiro: tópicos para análise circunstanciada de seus instrumentos de ação. RIAEE - Revista Ibero-Americana de Estudos em Educação, v. 11, n. esp. 3, p.1616-1625, 2016. DOI: https://doi.org/10.21723/riaee.v11.n.esp3.9064

LIMA, M. S. C. Surdez, Bilinguismo e Inclusão: entre o dito, o pretendido e o feito. 2004. 261 f. Tese (Doutorado em Linguística Aplicada) - Universidade Estadual de Campinas, Campinas, 2004.

MEIRIEU, P. O cotidiano da escola e da sala de aula o fazer e o compreender. Porto Alegre: Artmed, 2005.

ROCHA, L. P.; REIS, M. B. F.; COSTA, V. B. Educação especial e inclusão: diálogos sobre pesquisa, políticas e práticas. RIAEE - Revista Ibero-Americana de Estudos em Educação, Araraquara, v. 15, n. esp. 1, p. 872-883, maio 2020. DOI: https://doi.org/10.21723/riaee.v15iesp.1.13501

SEBASITÁN-HEREDERO, E. ANACHE, A. A. A Percepção docente sobre conceitos, políticas e práticas inclusivas: um estudo de caso no Brasil. RIAEE - Revista IberoAmericana de Estudos em Educação, Araraquara, v. 15, n. esp. 1, p. 1018-1037, maio 2020. DOI: https://doi.org/10.21723/riaee.v15iesp.1.13514

ZAJAC, S. Questões sobre o ensino de língua portuguesa para surdos: um novo olhar, novas perspectivas. 2011. 144 f. Tese (Doutorado em Linguística Aplicada e Estudos da Linguagem) - Pontifícia Universidade Católica de São Paulo, São Paulo, 2011. 


\section{Como referenciar este artigo}

CALIXTO, H. R. S.; RIBEIRO, A. E. A.; BRASILEIRO, T. S. A. Tensões entre políticas públicas e educacionais e in(ex)clusão de alunos surdos: ecos de um silenciamento? Revista Ibero-Americana de Estudos em Educação, Araraquara, v. 15, n. esp. 3, p. 2429-2445, nov., 2020. E-ISSN: 1982-5587. DOI: https://doi.org/10.21723/riaee.v15iesp3.14450

Submetido em: 20/07/2020

Revisões requeridas em: 30/08/2020

Aprovado em: 29/09/2020

Publicado em: 30/10/2020 